\title{
LA (RE)CONSTRUCCIÓN DE LA IDENTIDAD EN LA NARRATIVA JUVENIL GALLEGA. ENTRE LA ÉPICA Y LA MEMORIA HISTÓRICA
}

\author{
Isabel MOCIÑO GONZÁLEZ \\ Universidad de Vigo \\ imocino@uvigo.es
}

\section{Introducción}

La identidad de los pueblos se ha construido siempre sobre ejes simbólicos relacionados con su territorio y su historia a través de un proceso compartido en el ámbito social y de desarrollo colectivo. La situación particular que Galicia ha vivido con respecto al Estado español, los avatares históricos del último siglo y las particulares circunstancias que han condicionado su desarrollo cultural se reflejan en la evolución de la Literatura Infantil y Juvenil, que pasó por un complejo proceso de formación y consolidación, de extensión cronológica reducidísima en el que han incidido una serie de factores socioculturales nada fáciles de someter a esquema (Roig, 2001; 2005).

Como cultura emergente, la lengua se convirtió en uno de los símbolos más emblemáticos de su programa ideológico, al ser uno de los elementos fundamentales para la identificación de una nación (Figueroa, 2001: 83) y por actuar como «caja de resonancia» de sus pretensiones. Estos postulados hicieron necesario poner en funcionamiento un conjunto de estrategias que permitiesen a la lengua gallega dignificarse y que su radio de uso no quedase restringido a la oralidad, sino que se ampliase a otros ámbitos más formales, reservados hasta el momento al castellano, es decir, a los espacios que Jürgen Habermas denomina de la «publicidad». De igual modo, la restitución de la lengua gallega y el reconocimiento oficial, fundamentalmente a partir de la aprobación del Estatuto de Autonomía (1981), llevaría pareja la recuperación de la literatura, otro de los discursos más sólidos en la configuración de las naciones por su alta capacidad para construir la cohesión sociocultural en un territorio determinado por toda la carga ideológica que puede transmitir a través de sus textos y porque cualquier poder político que se precie debe contar con un sistema literario que le proporcione prestigio y poder simbólico (Even-Zohar, 1994). 


\section{La Literatura Infantil y Juvenil gallega}

En la conformación y consolidación de la Literatura Infantil y Juvenil es imprescindible referirse a la institución escolar, que desarrolló un papel fundamental al abrir sus puertas a la lengua gallega y a su literatura, así como al conocimiento de la historia, geografía y cultura propias. De hecho, entre los escritores con trayectorias más consolidadas y reconocidas en la actualidad en el sistema literario infantil y juvenil figuran docentes ${ }^{1}$ que se convirtieron en muchos casos en creadores, obligados por la falta de materiales y obras de calidad en lengua gallega y que se comprometieron con este sistema, primero como improvisados autores de textos didácticos y literarios dirigidos a la infancia y juventud, después, como reconocidos creadores de un sistema literario que demostró su capacidad de innovación y autonomía de una cultura emergente camino de la descolonización (Agrelo, 2012: 15-38).

Entre las vías para reafirmarse como cultura diferenciada, nos centraremos en algunas tendencias y corrientes presentes en la narrativa juvenil gallega que, desde diferentes modalidades formales y temáticas, recrea elementos de carácter identitario, en el sentido manifestado por Anne Marie Thiesse (1999: 133-158), de expresiones artísticas que recurren a elementos simbólicos y materiales como fundamentales para la identificación de una nación, entre los que Antón Figueroa (2001: 83) destaca, retomando a esta estudiosa, el recuerdo de antepasados históricos; héroes paradigmáticos de virtudes nacionales; conservación o recuperación de una lengua propia; referencias y orgullo de monumentos histórico-culturales; folclore propio; forma de vida en general con características específicas; lugares y paisaje característicos; símbolos representativos (himno o bandera); identificaciones pintorescas, etc., con los que se quiere reafirmar el hecho diferencial de la cultura gallega frente, fundamentalmente, a la castellana, que durante siglos mantuvo una posición dominante. Un conjunto de elementos sociosemióticos que han producido un importante número de textos con la finalidad de justificar, sancionar o fundamentar la existencia, el interés y la pertinencia de la cultura gallega (Even-Zohar, 1994: 369).

Por todo ello, en este trabajo el objetivo es observar las perspectivas adoptadas por los creadores gallegos en las novelas juveniles que se publicaron desde la década de los ochenta y que, en algunos casos, se sitúan en una frontera de límites difusos entre la literatura para adolescentes y jóvenes y la llamada institucionalizada o de adultos, a las que diferentes estudiosos se han referido como literatura de frontera (Roig, 2008a) o también crossover fiction (Beckett, 2008). Estas propuestas se caracterizan por sus guiños a la cultura juvenil y a las imágenes que la representan, al considerar a estos lectores potenciales como fundamentales en la génesis y construcción del sentido de las obras, aunque en ellas hay una eliminación progresiva y consciente de marcas que restrinjan los destinatarios preferenciales.

Para el estudio se seleccionan obras que, como producciones individuales, son aportes a la identidad colectiva porque, como señaló Even-Zohar (1993: 444), por medio de la literatura, el sistema cultural cuenta con un repertorio de modelos semióticos a través de los cuales «el mundo» se explica con un conjunto de narraciones que transmiten sentimientos de solidaridad, de pertenencia y, sobre

\footnotetext{
${ }^{1}$ Muchos de ellos involucrados en los colectivos de renovación pedagógica que desde los años sesenta y, sobre todo, setenta impulsaron un cambio fundamental en la práctica docente. A este grupo de autores y autoras más comprometidos con la Literatura Infantil y Juvenil se les denomina «Xeración do 68» (Roig, 2014).
} 
todo, de sumisión a leyes y decretos que no pueden ser impuestos sólo con la fuerza física y que pueden modificar, aunque sea de forma modesta, la identidad colectiva. Por eso, tratamos de observar como la literatura juvenil acercó a los jóvenes perspectivas nuevas desde las que reflexionar sobre la necesidad de adoptar posturas activas de reconocimiento de las características diferenciales de la cultura y también de valores que se instauraron en la sociedad democrática, cuestionando los modelos patriarcales dominantes hasta entonces y acercándose, de modo crítico, a acontecimientos históricos que marcaron el devenir de los pueblos.

Dado que la identidad se construye en el tiempo, el estudio de la producción literaria se centra en novelas juveniles que fueron publicadas en las tres últimas décadas y a través de éstas se intenta observar como el lectorado joven ha accedido a unos productos que se sitúan en paradigmas identitarios que consolidan nuevas estructuras de poder y valores colectivos, en un primer momento desplazándose hacia ámbitos representativos alejados del presente y mitificadores de espacios y tiempos distantes (Figueroa, 1988: 33), después recurriendo a novelas en las que el período histórico de la guerra civil española ocupa un lugar central, acercándose a una realidad silenciada y desconocida para muchos lectores potenciales. De un modo u otro, construyendo un pasado mitificado o abordando aspectos de un pasado relativamente reciente, los creadores gallegos potencian factores relativos al mundo globalizado para conformar elementos identitarios propios, que a la vez quieren ser piezas universales.

\section{Entre la épica y la memoria histórica}

Mediada la década de los años 80 se inició la publicación de modo continuado en lengua gallega de obras dirigidas al público adolescente y juvenil, impulsadas sin duda por la aprobación de la Ley de Normalización Lingüística $(1983)^{2}$ y la necesidad de ofrecer lecturas literarias adecuadas a las necesidades de los niveles más altos de escolarización obligatoria ${ }^{3}$.

En este primer momento, mientras en la narrativa infantil se observa un gran peso de la adecuación consciente a los criterios del utilitarismo curricular, al responder a encargos editoriales con el propósito de cubrir necesidades instrumentales de los centros educativos, la narrativa ju venil, aunque menos numerosa, experimenta un mayor auge y abre nuevas corrientes formales y temáticas, una capacidad de innovación que llevó al incipiente sistema literario infantil y juvenil a situarse en pocos años en pie de igualdad con otras literaturas próximas, con las que inició un camino de diálogo y múltiples relaciones e intercambios, tanto por la excelente acogida que los creadores gallegos tuvieron

\footnotetext{
${ }^{2}$ Que había sido precedida por importantes pasos, como la aprobación del Decreto de Regulación de la Incorporación de las lenguas nativas a la enseñanza básica en 1975, el Decreto de Bilingüismo de 1979 y, sobre todo, del Estatuto de Autonomía en 1981, marco legal en el que poder desarrollar esta Ley.

${ }^{3}$ Con anterioridad fue Xosé Neira Vilas quien publicó una novela fundacional de la narrativa juvenil, Memorias dun neno labrego (1961, 1968), una obra ambivalente que se convirtió en un auténtico best-seller, reeditándose de modo constante y traducida a múltiples lenguas.
} 
en certámenes literarios nacionales e internacionales ${ }^{4}$, como por las vías de visibilización que se fueron abriendo a partir de ese momento para esta producción, que fue resultado de unas nuevas coordenadas sociológicas que exigían una cada vez mayor oferta de lecturas para un sector potencial de consumidores en aumento (Roig Rechou, 2014).

Tomando como referencia este marco temporal, nos detendremos fundamentalmente en dos tendencias en las que el tratamiento de elementos de carácter identitario es de gran relevancia, siguiendo una línea de reivindicación que se venía cultivando desde el inicio de la Literatura Infantil y Juvenil en la década de los sesenta y setenta. Estas tendencias generales se concretizan de modo claro en:

1. novelas épicas, en las que se recrea una Galicia mítica y un universo legendario, se parte de un material ancestral que se reivindica como punto de partida válido para un proceso de transformación social y colectiva en el que los jóvenes están llamados a participar activamente, por lo que se recurre a la ficción literaria para modificar y direccionar la identidad a través de un acercamiento afectivo a diferentes elementos que impulsan a un compromiso activo con la tierra y la historia gallega;

2. novelas de recuperación de la memoria histórica, en las que se abordan hechos y ambientes derivados de conflictos bélicos, en especial la guerra civil española, dando a conocer entre los jóvenes una historia reciente ignorada, a veces a causa del silencio y la resignación, una mirada hacia el pasado para comprender heridas y fracturas que siguen repercutiendo en la sociedad actual y que hay que conocer para evitar que vuelvan a ocurrir en el futuro.

En cada una de estas tendencias destacaremos las obras más relevantes por su calidad literaria, avalada en muchos casos por la concesión de premios, las constantes reediciones, las traducciones a otras lenguas o la influencia que ejercieron en la producción posterior.

\section{Reconstrucción de un pasado mitificado}

Entre las novelas fundacionales de la literatura juvenil gallega se sitúan aquellas que se aproximaron a las corrientes temáticas más prolíficas de la literatura de adultos, tales como la creación de una épica nacional y de modelos identitarios nacionales con la intención de reconstruír la sociedad civil que vivía de espaldas a su identidad y anclada en modelos sociales que necesitaban de un giro, como ocurría, por ejemplo con el rol desempeñado por la mujer (Roig, 2011a: 11).

En la construcción de un espacio y pasado mitificado desde el que se reivindican elementos configuradores de una identidad propia destacan aquellas novelas que echan mano de la tradición

\footnotetext{
${ }^{4}$ Piénsese en los cuatro Premios Nacionales otorgados a Paco Martín, Xabier P. Docampo, Fina Casalderrey y Agustín Fernández Paz, o en el Pier Paolo Vergerio que recibió Antonio García Teijeiro, además de la prolífica representación de autores gallegos en otros certámenes nacionales como el Lazarillo, por poner sólo algunos ejemplos.
} 
literaria culta, fundamentalmente la Materia de Bretaña, en una relectura que combina referencias a la actualidad con el pasado caballeresco y los rasgos de la novela de iniciación con la intertextualidad con personajes y obras claves en la literatura artúrica. Entre los creadores que iniciaron esta línea figura Xosé Luís Méndez Ferrín (Ourense, 1938), un escritor de referencia en la literatura institucionalizada gallega que publicó la novela de aventuras e iniciación Arnoia, Arnoia (Xerais, 1985), incluída en la Lista de Honra del IBBY en 1988 y que destaca por los múltiples niveles de lectura que ofrece, integrándose como una pieza más del macrotexto que configura la producción de este autor 5 .

Destaca en la obra la recurrencia a denominaciones exóticas de espacios y personajes, de símbolos de libertad y felicidad, así como la fantasía puesta al servicio del misterio y el enigma, la ausencia del humor y la alegoría política (Tarrío Varela, 1994: 354). Un universo cargado de referencias míticas y literarias en el que se recrea el viaje iniciático de un adolescente, que aproxima al lector a otras modalidades como las novelas de piratas, las culturas orientales o las referencias al universo tolkiano, abordado desde lo onírico. Un rico diálogo intertextual en el que destaca también el gran conocimiento de la tradición propia que demuestra Méndez Ferrín, plasmado en la recreación de una Galicia mítico-idealizada que se convierte en metáfora de un sueño de futuro: aquel en el que la juventud tome las riendas de su tiempo y lleve a su patria al esplendor perdido.

El éxito de recepción de la obra fue inmediato ${ }^{6}$ y se convirtió en referencia para creadores posteriores, que siguieron recreando el pasado mitológico y la configuración de una épica nacional, como hace Carlos G. Reigosa (Pastoriza, Lugo, 1948) en Irmán rei Artur (Xerais, 1987), en la que reúne un conjunto de relatos que, significativamente, cuentan con un prólogo del propio X. L. Méndez Ferrín, situando brevemente la relevancia de la tradición literaria de la Materia de Bretaña, y una introducción de León T. Vivanco, quien constata la intención de acercar esta obra al lector joven, por lo tanto reafirmando la clara voluntad de los editores de crear herramientas para la formación lectora de la juventud y materiales de apoyo curricular, tan escasos en esta primera etapa del sistema literario infantil y juvenil gallego. Es probablemente por eso que el propio autor firme un prólogo titulado « Viva o Rei Artur!», en el que analiza la importancia de la literatura que toma como referencia en los relatos reunidos en la obra, orientando la lectura y ofreciendo otras fuentes complementarias a la original historia de Lanzarote ${ }^{7}$, Merlín y el rey Arturo, personajes emblemáticos de esta tradición literaria, con la que se establece un rico diálogo intertextual, a la vez que se remite a múltiples obras

\footnotetext{
${ }^{5}$ Considerada por Tarrío (1994: 352) un artefacto, es decir, un sistema estético en el que cada una de las partes está íntimimamente interrelacionada con todo el conjunto y, a su vez, por un efecto de retroalimentación o de feed back, explica las fases cronológicamente producidas con anterioridad.

${ }^{6}$ E incluso provocó que otras obras del autor dirigidas al público en general se incluyesen en colecciones juveniles, como Retorno a Tagen Ata (Xerais, 1987) y Amor de Artur-Fría Hortensia (Xerais, 1987), en las que continúa la recreación de este particular mundo mítico, aunque no recibieron la misma respuesta del lectorado, probablemente por un mayor grado de cripticismo y dificultad de comprensión, dadas las grandes dosis de simbolismo y alegoría que presentan.

${ }^{7}$ El relato protagonizado por este héroe había sido premiado en el $\mathrm{X}^{\circ}$ Concurso «Modesto R. Figueiredo», un certamen de la literatura institucionalizada que dio lugar a la publicación del volumen recompilatorio Premios Pedrón de Ouro 1985. 1986 (Ediciós do Castro, 1987).
} 
canonizadas del sistema literario gallego, como las de Ramón Cabanillas, Álvaro Cunqueiro y el propio X. L. Méndez Ferrín ${ }^{8}$.

Dentro de los paradigmas que quieren fijar nuevos modelos identitarios nacionales y la recreación de mundos míticos se sitúa también María Xosé Queizán (Vigo, 1939), una reconocida autora de la literatura institucionalizada y feminista, que refleja en toda su obra una perspectiva cuestionadora de las estructuras patriarcales. También en la novela de iniciación $O$ segredo da pedra figueira (Tintimán, 1985) ${ }^{9}$, que se integra plenamente en los presupuestos ideológico-discursivos que la creadora practicaba desde hacía años y que fueron objeto de sus investigaciones y de muchas de sus actividades públicas. Al igual que Méndez Ferrín, recurre también a la recreación de un distante pasado legendario, en el que el protagonista es un pueblo que busca una nueva tierra que, como señala Montse Pena (2012: 454), es asociable a la postura que la sociedad gallega se ve obligada a asumir tras la llegada de la democracia. Un texto que propicia diferentes lecturas, al poder interpretarse como una épica de carácter identitario, pero también como una novela de genealogía femenina y feminista, dado que son tres las mujeres que asumen el protagonismo. En este sentido destaca en la obra la subversión de los roles femeninos, una apuesta innovadora, retomada después por muchos creadores y creadoras que se sensibilizaron con la importancia de atender a los papeles ficcionales otorgados a los roles de género y ofrecer modelos más acordes con la sociedad del momento y los cambios que en ella se estaban operando ${ }^{10}$.

Por lo tanto, en esta novela Queizán reivindica dos tipos de identidad marginalizada, la nacional del pueblo gallego y la femenina, a través de un relato iniciático y de aventuras, que se plasma en la búsqueda de los propios orígenes y de resistencia ante pueblos opresores. Una parábola contra el poder patriarcal, que recrea la evocación de diversos aspectos de la geografía, historia, transmisión oral y mitología gallegas, situándose en una clara línea de reivindicación feminista (Blanco, 1991: 210; Roig y Neira, 2010: 338).

La recreación de elementos de carácter identitario continuó en los primeros años del siglo XXI, ahora puestos al servicio de un intenso diálogo con la tradición oral y con el mundo mítico de origen y reminiscencias celtas, que es ficcionalizado por Suso de Toro (Santiago de Compostela, 1956) en Morgún (Lobo Máxico) (Xerais, 2003), una novela de excelente calidad literaria en la que se recrea

\footnotetext{
${ }^{8}$ La recreación y relectura del ciclo artúrico no se limita a estas dos obras, sino que continuó posteriormente de la mano de autores mucho más jóvenes, como Eva Moreda (Asturias, 1981) que con su primera novela, Breogán de Guisamonde, o cabaleiro da gaivota (Fundación CaixaGalicia, 1997), ganó el Premio Rúa Nova de Narracións Xuvenís en 1997; y Xabier López López (Bergondo, A Coruña, 1974) en Cando Artur non era rei (Galaxia, 2012), que presenta muchas concomitancias con estos títulos pioneros, al publicar una novela amparada en un amplio aparato paratextual que revela las fuentes y ofrece un itinerario muy interesante de lecturas, además de un intenso diálogo intertextual con estos y otros autores canonizados de la literatura gallega, aspecto que resulta muy significativo al incidir en los mismos elementos que se pusieron en valor casi tres décadas antes (Mociño, 2013: 43).

${ }^{9}$ Publicada inicialmente de la mano del sello Tintimán, creado en Vigo al amparo de la revista homónima, en 1989 fue reeditada por Edicións Xerais de Galicia en la colección «Xabarín», en la que se introducen paratextos dirigidos al lectorado potencial, como la introducción de Carme Blanco, en la que se ofrecen claves de lectura de la obra, elemento que desaparece al incorporarse a la colección «Fóra de xogo». Un proceso de edición de la obra que fue estudiado por Fernández (2012).

${ }^{10}$ Línea que había iniciado Xohana Torres en el cuento Pericles e a balea (1983) y que fue continuada posteriormente por autoras como Úrsula Heinze, Helena Villar Janeiro, María Victoria Moreno o Ana María Fernández, entre otras (Blanco, 1991; Roig y Neira, 2010).
} 
una mitología épica del pueblo gallego, que representa a través de los héroes la autenticidad y valor de lo propio, adquiriendo una gran importancia la geografía y la antroponimia. Además se detecta, como en los autores que le precedieron, el mensaje explícito de denuncia por el sometimiento que lleva a la lucha contra el opresor y en la que se reflejan algunas de las injusticias presentes en la sociedad actual. Una historia antigua, datada alrededor del siglo XIV, en la que se parte del recurso del manuscrito encontrado para recrear un mundo que asienta en una gran violencia y en las venganzas de los que, movidos por el afán de poder, manejan un universo en el que sólo la magia y los dioses serán capaces de poner fin a tanta ferocidad.

También en estos años se retomó esta tendencia en series literarias, que experimentaron un gran auge y a través de las que es posible que se busque la fidelización del lectorado, aunque no es un fenómeno nuevo ni se puede atribuír a la cultura actual pues, como señala Victoria Sotomayor (2001: 42), tiene mucho que ver con la naturaleza misma de la literatura y se encuentra en todas las épocas, de una u otra forma, aunque en la narrativa juvenil gallega no se había producido con anterioridad. Entre los creadores que adoptaron esta fórmula literaria en su incorporación al subsistema juvenil cabe destacar a Xesús Manuel Marcos (Seoane do Caurel, 1967), que después de recibir numerosos premios de relato corto publicó dos entregas de una serie de aventuras épico-fantásticas titulada genéricamente O Brindo de ouro. La primeira entrega A chamada do Brindo (Xerais, 2004) ${ }^{11}$ recibió el Premio Merlín 2004, uno de los más prestigiosos en el sistema infantil y juvenil gallego, y entró a formar parte de la lista de The Withe Ravens en 2005; la segunda, por el momento última, es A táboa da Hospitalidade (Xerais, 2009).

Entre los aspectos más destacables de la serie cabe señalar la ambientación del universo míticolegendario en una zona concreta de Galicia, la Serra do Courel, en la provincia de Lugo, que es fácilmente identificable por el excelente trabajo de recuperación de la toponimia y múltiples referencias a su geografía real, combinadas con otras de carácter mágico. También por presentar una acción trepidante en la que no deja de intercalar pormenorizadas descripciones de los lugares por los que transcurre la acción y que presentan un léxico muy rico que remite a un evocador espacio de conservación de las tradiciones. Con estas obras, Marcos crea un sugerente mundo ficcional que intertextualiza con el de autores de la literatura universal como Tolkien, Lovecraft o Michael Ende, y en el que destacan valores como la amistad, la fortaleza y una profunda reflexión sobre la ambición que domina a los seres humanos ${ }^{12}$ (Roig, 2008a: 22-23/116).

Entre las últimas incorporaciones a la literatura seriada que contó con una excelente recepción de público y crítica cabe señalar a Elena Gallego Abad (Teruel, 1969), que en la trilogía «Dragal» se sitúa en la línea mítico-legendaria. Compuesta por A herdanza do dragón (2010), finalista do IV

\footnotetext{
${ }^{11}$ Fue traducida al castellano por Anaya en 2008 con el título El brindo de oro.

${ }^{12}$ Elementos claves en esta serie que también utiliza el autor en la novela de aprendizaje $O$ esconxurador (Galaxia, 2010), en la que continua recreando la mitología popular y los saberes tradicionales, desde el protagonismo femenino, la asunción de la diferencia y la comunicación entre el mundo mítico y el real, en la línea de la novela de María Xosé Queizán $O$ segredo da pedra figueira, por cuanto la protagonista se transforma en mujer y decide sobre su futuro, renunciando a los poderes sobrenaturales para vivir entre los mortales.
} 
Premio CaixaGalicia de Literatura Xuvenil 2009 y Premio Frei Martín Sarmiento; A metamorfose do dragón (2011) y A fraternidade do dragón (2012), fue publicada por Edicións Xerais de Galicia y se está reeditando con asiduidad ${ }^{13}$. A diferencia de las propuestas de Xesús Manuel Marcos, Elena Gallego Abad no recurre al pasado distante sino que, a partir de la sociedad actual, recrea la intromisión de un mundo legendario. Un sugestivo universo que se enriquece en la obra a través de la convergencia de múltiples rasgos de las novela de aventuras, policíacas, detectivescas y de iniciación, además de acercar al lectorado un rico mosaico de referencias culturales, artísticas, históricas y fantásticas, que enlazan con la tradición culta y popular, reescribiéndola y actualizándola.

Estas referencias a la identidad colectiva configuran el contexto en el que se desarrolla la búsqueda y construcción de una identidad individual, la del adolescente protagonista, que se descubre heredero de una saga antigua y sufre una metamorfosis en forma de dragón, cumpliéndose así la profecía del renacimiento del último dragón gallego. Un duro proceso que se inscribe en las coordenadas de otras series actuales, sin ir más lejos, la de Harry Potter, en el sentido de presentar a un protagonista que se ve aislado e incomprendido, que parte de una carencia afectiva, en este caso por la muerte del padre, cuenta con la ayuda de una inteligente muchacha, de la que acaba por enamorarse, y posee además un amuleto protector, que le guía en la búsqueda de esa identidad por descubrir y los poderes que heredó de su saga familiar (Ferreira da Silva, 2011: 114-115). En definitiva, una relectura de la eterna lucha del bien contra el mal, los miedos e inseguridades propios de la adolescencia en la sociedad actual, la dualidad del ser humano y el descubrimiento progresivo de la identidad personal, que se integra en una historia marcada por el legado cultural que configura la tradición gallega y también universal.

En general se observa que desde el inicio de la narrativa juvenil gallega el recurso a la mitología fue una vía seguida primero por autores que provenían de la literatura institucionalizada o de adultos pertenecientes a diferentes generaciones biológicas ${ }^{14}$, que permitieron que sus obras se incluyesen en colecciones juveniles dirigidas al incipiente lectorado que accedía a la lengua gallega a través de las etapas más altas de escolarización obligatoria. Por su parte, probablemente los editores responsables de estas colecciones recurrieron a voces consolidadas para aprovechar el prestigio con el que ya contaban en la literatura de adultos y atraer con más eficacia a los jóvenes. Además se observa que esta tendencia no dejó de ser visitada con asiduidad por autores más jóvenes, que ahora publican en ambos sistemas literarios, infantil y juvenil y de adultos, sin complejos, aprovechando las posibilidades que ambos les ofrecen para promocionar sus obras.

\section{Recuperación de la memoria histórica}

\footnotetext{
${ }^{13}$ Prueba del éxito de público es la sexta edición que está ya publicada de la primera entrega y las opiniones de críticos que sobre la obra se pueden consultar en los Informes de Literatura correspondientes (Roig, 1996-2013) (www.cirp.es).

${ }^{14}$ A los que Roig Rechou (2002) denominó, amparándose en el modelo de unidades generacionales de René Wellek y Karl Mannheim, «Literatura e Literatura Infantil e Xuvenil», y posteriormente combinando esta propuesta metodológica con el modelo biológico propuesto por José Ortega y Gasset y Julius Perterson, «Da literatura institucionalizada á narrativa xuvenil» (Roig, 2014).
} 
Si en el inicio de la narrativa juvenil gallega una de las tendencias fue dar a conocer un pasado mitificado, alejado en el tiempo y configurador de una cultura diferenciada, en la década de los noventa se inició la publicación de obras en las que se muestra la preocupación por acercarse a períodos más recientes de la historia, que se materializó, entre otros aspectos, en la ficcionalización de las consecuencias de la guerra civil española, temática que, como señala Roig Rechou (2008b: 73), sólo había sido tratada muy secundariamente en tres obras consideradas ambivalentes: Memorias dun neno labrego (1961/1968), Cartas a Lelo (1971) y Aqueles anos do Moncho (1977), de Xosé Neira Vilas, y en las que el conflicto aparece aludido o recordado, como un mero telón de fondo ${ }^{15}$.

Instaurada la Democracia y con un sistema literario que daba pasos firmes hacia la consolidación, los creadores gallegos se acercaron a un episodio histórico dramático silenciado hasta el momento, una inquietud que se acentuó a inicios del siglo XXI cuando la temática toma un nuevo impulso y se hace más presente en los catálogos juveniles, reflejo de una sociedad que no podía seguir ajena a una fractura tan importante en su historia reciente. Estas voces pioneras, que desde la ficción reivindicaban la necesidad de la recuperación de la memoria histórica y de dar a conocer entre los jóvenes un episodio reciente de la historia, se vieron amparadas por la declaración en el año 2006 en el Estado español del «Año de la Memoria Histórica», la promulgación de la llamada Ley de la Memoria Histórica y la creación de instituciones como el Centro Documental de la Memoria Histórica (2007), en el que se integró el Archivo General de la Guerra Civil Española y otros fondos procedentes de nuevas adquisiciones y/o convenios con entidades públicas y privadas (Roig et alii, 2009: 57-58). Unos eventos, normas y leyes que dieron como resultado iniciativas que llevaron a que términos como «reconocimiento»o «reparación» se convirtiesen en protagonistas y que muchos de los temas que se invita a recordar (localización e identificación de las víctimas, destrucción de símbolos y monumentos públicos que ensalzan la represión franquista, el exilio...) se reflejasen en el aumento considerable de bibliografía en todos los ámbitos de la cultura, entre ellos también en la literatura para la niñez y la juventud (Roig Rechou, 2011b: 165-166).

La producción resultante hasta el momento cuenta ya con estudios rigurosos realizados por especialistas en Literatura Infantil y Juvenil, como los debidos a los miembros de la Red Temática de Investigación LIJMI ${ }^{16}$ : A guerra civil española na narrativa infantil e xuvenil (Roig, Lucas y Soto, 2008) o los derivados del proyecto de investigación desarrollado por parte de los miembros de esta red, «La guerra civil española en la narrativa infantil y juvenil (1975-2008)» ${ }^{17}$ (2009-2012), recogidos en La guerra civil española en la narrativa infantil y juvenil (1936-2008) (Roig, Ruzicka, Ramos: 2012) y The Representations of the Spanish Civil War in European Children's Literature (1975-2008)

\footnotetext{
${ }^{15}$ Para un estudio más pormenorizado de esta temática en las obras de Xosé Neira Vilas, ver Roig (2012: 529-548).

16 «Las Literaturas Infantiles y Juveniles del Marco Ibérico e Iberoamericano», coordinada por la profesora de la Universidad de Santiago de Compostela desde el año 2004, Blanca-Ana Roig Rechou. Más información en http://www.usc. es/gl/proxectos/lijmi/.

${ }^{17}$ Para más información sobre el desarrollo y configuración de este proyecto ver: B. A. Roig Rechou y V. Ruzicka Kenfel (2011), «La Guerra Civil española en las narraciones infantiles y juveniles. Un proyecto de investigación», en A.M. Ramos e I. Mociño González (eds.). Crítica e Investigación en Literatura Infantil y Juvenil/Crítica e Investigação em Literatura Infantil e Juvenil, Braga/Vigo: ANILIJ/CIEC, col. Estudos, nº 1, pp. 321-335.
} 
(Roig y Ruzicka, 2013). Son trabajos que combinan múltiples enfoques y perspectivas teóricas, que permiten acercarse al tratamiento de esta temática en diferentes literaturas infantiles y juveniles, entre ellas la gallega ${ }^{18}$, y también observar como los creadores adoptaron diferentes perspectivas, desde la guerra vivida, la recordada, la referida o la aludida (Bertrand de Muñoz, 1982; Arén, 2006).

Centrándonos en la producción juvenil que trata la guerra civil se observa que en la mayor parte de los casos son novelas protagonizadas por adolescentes que investigan y descubren episodios ocurridos antes o durante el conflicto. Novelas de aprendizaje en las que se refleja tanto el proceso de maduración, que contribuye a la toma de conciencia de la identidad individual, como una nueva mirada sobre la identidad colectiva, especialmente en el caso de los perdedores, que aflora a medida que el pasado se revela y con él la historia de muchas familias.

Entre los autores pioneros en la ficcionalización de esta temática se sitúa el poeta Antonio García Teijeiro (Vigo, 1952) que publicó la novela A teima de Xan (Sotelo Blanco, 1991; Galaxia, 2005), un diario de adolescencia en el que aparecen transcritos hechos del pasado que componen un retrato de las relaciones familiares y sociales, revelando desde la perspectiva temporal la alienación infringida por la ideología imperante, la censura y el silenciamiento a maestros republicanos, como el tío del protagonista, Camilo «O Peixoto», que representa a los denominados exiliados interiores, purgados y apartados del ejercicio de su profesión (Neira, 2008: 289), de una ideología y metodología pedagógica de maestros y maestras que fueron condenados al ostracismo, como la propia cultura gallega. Un texto cargado de emociones y sentimientos que se configura como un homenaje a todos los represaliados, en una obra que se erige como grito contra el silencio que se cierne sobre episodios de la historia reciente y la propia conciencia de la identidad gallega, en un primer intento de recuperación, por la vía de la ficción, de una memoria robada durante décadas a los jóvenes ${ }^{19}$ (Roig, 2008b: 79; Roig, 2009: 13-17; Roig, 2011: 159-183; Roig, Ruzicka e Ramos, 2012: 121-123).

Esta línea iniciada por García Teijeiro se convirtió en recurrente en las obras de Agustín Fernández Paz (Vilalba, Lugo, 1947), una de las voces más significativas en el sistema literario infantil y juvenil gallego en lo que al género narrativo se refiere y cuya producción incluso ha transcendido, a través de la traducción, a otros sistemas literarios, sobre todo del marco ibérico (ámbitos castellano, catalán, vasco y portugués).

Sus obras sobre esta temática han sido analizadas por la crítica bajo las etiquetas de «ciclo de las sombras» $\mathrm{o}$ «trilogía de la memoria», denominaciones en las que la palabra «sombras» es recurrente y funciona como «símbolo de la memoria de los muertos en la guerra civil, así como del oscurantismo,

\footnotetext{
${ }^{18}$ En la que se viene trabajando sobre esta temática desde hace años, como se refleja en la antología A memoria das guerras na narrativa infantil e xuvenil en lingua galega (Xerais/Galix, 2004), coordinada por María Jesús Agra Pardiñas y BlancaAna Roig Rechou; o monografías como Grandes autores para pequenos leitores (Deriva, 2007), coordinada por José António Gomes y Blanca-Ana Roig Rechou, por citar dos ejemplos.

${ }^{19} \mathrm{Y}$ que se fue recuperando a través de la historia de los niños de la guerra en Tristes armas (Xerais, 1994), de Marina Mayoral; memorias de infancia como A encrucillada da torre (Galaxia, 1994), de Xosé Ramón González Álvarez; y A serra máxica. Memorias de Nadal dun neno da posguerra española (Ediciós do Castro, 1998), de Xavier Lorenzo Oroza; o la reflexión sobre la influencia del pasado en el presente y los silencios y vacíos tratados en Neve en abril (Fundación Caixa Galicia/Biblioteca Nova 33, 1996; Galaxia, 2005), de Inma López Silva.
} 
el silencio y el desconocimiento que los rodean» (Soto, 2008: 254), mientras que el término «memoria» enlaza con la preocupación del autor por dar a conocer a las generaciones más jóvenes la verdad y no versiones parciales o distorsionadas de la historia. Busca también provocar la memoria del público lector y conseguir que no se entierre el pasado sin antes conocerlo por completo (Roig, 2010: 164).

De este modo Fernández Paz en Noite de voraces sombras (2002), Tres pasos polo misterio (2004) y Corredores de sombra (2006), publicadas por Edicións Xerais de Galicia en la colección «Fóra de xogo», ficcionaliza su preocupación por recuperar la memoria de las víctimas tanto de la guerra como de la posguerra para intentar cerrar definitivamente las heridas provocadas por el conflicto, abriendo las fosas del pasado y devolviendo la dignidad a los muertos ignorados. Para ello emplea múltiples referencias culturales y citas, tanto literarias como musicales, en historias en las que el amor funciona como elemento fundamental para la recuperación del pasado y hace verosímil los descubrimientos que llevan a cabo las protagonistas y las relaciones entre los bandos enfrentados, al buscar apoyo y testimonios entre los adultos que vivieron de lleno la confrontación (Neira, 2007: 8081; Roig, 2008b: 82).

En la línea de García Teijeiro, Fernández Paz también recurre a la figura de los maestros represaliados en Noite de voraces sombras, novela de iniciación en la que se abren vías de comunicación con el pasado silenciado a través de lo paranormal, recordando lo ocurrido para hacer justicia con los perseguidos y asesinados (Soto, 2008: 251-269). Configura así un retrato de una Galicia que pasó de la esperanza en un futuro mejor al desasosiego y al terror ante el alzamiento fascista, por lo que la obra se convierte, según ha afirmado en diferentes ocasiones el propio autor, en un homenaje a los maestros republicanos que fueron represaliados y en un intento de recuperar el eslabón perdido entre la generación que sufrió directamente la represión y las más jóvenes (Roig, 2004: 162; Roig, 2011b:169-172).

Además Fernández Paz incide en el retrato de las penurias que los presos padecieron en la isla de San Simón, lugar de gran relevancia para la historia y cultura gallegas, que ya en la Edad Media aparece en las cantigas medievales, y que después del conflicto se convirtió en prisión para miles de personas anónimas, representadas por personajes ficcionales, en un intento por simbolizar la memoria viva y transmitir también la tradición que recuerda que «los muertos no abandonan» (Roig, 2008a: 72 73/166-167), a través de los que se configura una historia de alcance universal (Soto, 2008: 269).

Este mismo afán está presente en Corredores de sombra, en la que se rescata la memoria de un asesinado a través de la historia de una joven que es capaz de hacer su contribución persoal a la memoria colectiva, a pesar de pertenecer a la estirpe de los ganadores y encontrar fuerzas suficientes para escribir y poder romper con los fantasmas familiares (Agrelo, 2012: 155-168). Es aquí la palabra la que se convierte en arma capaz de romper con el pasado y reparar el mal ocasionado, contribuyendo a la lucha de los que décadas después del conflicto intentan rescatar del abismo de la desmemoria a las víctimas. Una novela en la que confluyen recursos propios de las narrativas de misterio e intriga, de aprendizaje y de la novela de memoria que se convierte por la solvencia y agilidad de la escritura, la tensión de la trama y los sentimientos y reflexiones que de ella se desprenden, en un eficaz antídoto 
contra la desmemoria y en un magnífico puente hacia otras lecturas recomendables (Agrelo, 2012: 167; Roig, Ruzicka e Ramos, 2012: 214-215).

Por último, a esta serie pertenecen también los relatos de Tres pasos polo misterio, que habían sido publicados con anterioridad en volúmenes colectivos ${ }^{20}$ y que ahora el autor reescribe, una de las características del proceso creativo de Fernández Paz, que le imprime el carácter de obra en construcción. Proceso autorial que, como señala Isabel Soto (2009: 26), resulta curioso por inhabitual en el contexto de la literatura gallega actual y en el que parte de su convencimiento de que cualquier obra literaria nunca logra un remate claro y definitivo y siempre es posible encontrar un aspecto susceptible de ser modificado. En estos relatos, recurre también al terror, al misterio y a elementos de lo paranormal, además de introducir múltiples elementos que remiten a la construcción de la identidad, especialmente en lo referido a la vinculación con el imaginario de la cultura popular, creando siempre la atmósfera adecuada para cada caso (Roig, 2008a: 76/170).

Es de destacar en estas obras de Fernández Paz el afán por privilegiar la voz femenina sobre la masculina, mujeres que a medida que maduran se cuestionan su propia vida, se abren al mundo y observan la sociedad que les tocó vivir con una mirada más abierta y crítica, mostrando un espíritu inconformista y un carácter inquebrantable. Todas ellas forman parte de un proceso regenerativo en el que asienta una nueva sociedad, distanciada de los roles del modelo patriarcal, que somete y victimiza a las mujeres tanto del bando de los vencedores como de los vencidos. Este es uno de los aspectos más relevantes de una excelente novela de An Alfaya (Vigo, 1964), A sombra descalza (Xerais, 2006), Premio Lazarillo de Literatura Xuvenil 2005, Premio Neira Vilas 2006 e incluída en The White Ravens, en la que además de dejar sentir la influencia de la narrativa de Fernández Paz, también confiesa que es

[...] moi amiga da palabra «sombra», do que encerra como metáfora trasladada a todos os campos da vida literaria, e máis en concreto á época de escuridade da que tratamos, a un tempo onde todo estaba envolto nunha pátina de tebras, dor e desesperanza (Alfaya y Vázquez, 2009: 83).

Aspectos a los que se aproxima en una novela de frontera que evoluciona a través de dos planos dicotómicos, el de las sombras y el de los descubrimientos, que permiten comprender desde la actualidade las causas que provocaron la fragmentación familiar en dos bandos irreconciliables, vencedores y vencidos, y que se perspectiviza a través de la relación entre las mujeres de diferentes generaciones, víctimas de un enfrentamiento enconado, fraguado en el resentimiento y la evocación dolorosa del pasado (Agrelo y Mociño, 2008: 198-199; Roig, Ruzicka e Ramos, 2012: 211-212). Un rico retrato de las relaciones del contexto íntimo de estas mujeres que padecen desde el silencio, la culpa y el resentimiento grandes tensiones internas, secretos que sólo la más joven, una adolescente,

\footnotetext{
${ }^{20}$ Como es el caso de Contos do Museo. Relatos do Museo Provincial de Lugo (Deputación Provincial de Lugo/Museo Provincial de Lugo, 2003), en el que se incluye «A serpe de pedra»; Imos xuntos camiñar (Xunta de Galicia, 1999), que acoge «A vella foto das estrelas»; e Historias para calquera lugar (2001), con el que Edicións Xerais de Galicia conmemoró la publicación del número cien de la colección «Merlín» y en el que publicó «As sombras do faro».
} 
intenta descubrir para comprender y poder erradicar, «aireando» los espacios vitales para poder respirar y vivir con alegría.

De este modo, Alfaya recrea un universo femenino marcado socialmente por la situación de supeditación a lo masculino, pero en el que se van desvelando silenciosas redes de complicidad que procuran el fortalecimiento y la ayuda mutuas. Una forma de subversión que se convierte en un modo de resistencia pactada desde el silencio y acatamiento, hasta la ruptura que las nuevas generaciones, motor de cambio, buscan en el perdón que llevará a la reconciliación y a la cura de las heridas de la guerra y de las personas que la vivieron (Agrelo y Mociño, 2008: 202-203). De algún modo, la novela propicia la reflexión sobre el hecho de que la defensa férrea y atemporal de una ideología, acompañada por la incomprensión y la falta de voluntad para perdonar pueden llevar a una familia, y a la sociedad en general, hacia una convivencia asfixiante, dañina y dolorosa (Agrelo y Mociño, 2008: 205), por eso está en manos de los jóvenes mostrar la fortaleza y el valor para enfrentarse a la verdad desde una actitud de reivindicación del derecho a saber, como también hicieron Antonio García Teijeiro o Agustín Fernández Paz en sus obras sobre esta temática.

Han sido más las novelas juveniles que abordan la guerra civil desde perspectivas eminentemente femeninas, como Quen matou a Inmaculada de Silva (Xerais, 2009), de Marina Mayoral, o Xograres dun tempo novo (Everest, 2009), de Pepe Carballude, en las que se recurre a la rememoración y a la lucha por unos ideales que fueron aniquilados. Destaca en la segunda obra la aproximación a la época de la República y a la labor cultural de las Misiones Pedagógicas en las villas y pueblos de la Costa da Morte. Un tema de gran significación que, como señala Xosé Neira Vilas (2009: 4), las nuevas generaciones deben conocer y valorar, especialmente por el trabajo encomiable de intentar paliar las diferencias de oportunidades culturales entre el ámbito rural y el urbano. Un retrato histórico en el que se hace justicia con la memoria, con una época y con todas las personas que, como la protagonista, participaron activamente en este movimiento cultural y vieron sus vidas truncadas por la barbarie de la guerra. Vidas que asientan en historias de amor y militancia, que proyectan retratos íntimos y colectivos de una época histórica, convirtiéndose en homenajes a las víctimas, muchas de ellas intelectuales que sufrieron el exilio o perecieron por defender sus ideales de libertad.

\section{A modo de conclusión}

Por todo lo dicho, en la narrativa juvenil gallega se cuenta con un interesante corpus de novelas que revelan la preocupación de los creadores por incidir en los modelos identitarios. Se observa, desde el punto de vista temporal, que en las primeras novelas juveniles se optó por un distanciamiento consciente de la realidad y la recreación de mundos míticos, proyectando en la atemporalidad de un pasado remoto el ideal de futuro. Posteriormente otra línea muy transitada fue la de la recuperación de la memoria histórica, adelantándose incluso al movimiento social que se plasmó en un reconocimiento institucional, y que acercó a los jóvenes un hecho histórico silenciado durante décadas, haciéndoles conscientes de los sufrimientos que las luchas fratricidas provocan en la sociedad. En cada una de estas 
novelas se configura un retrato colectivo, en el que se integra de modo significativo también la construcción de la identidad individual, incidiendo en muchos casos en cuestiones genéricas, que propician la reflexión sobre la necesidad de vivir en una sociedad más igualitaria.

\section{Referencias bibliográficas}

AgRelo Costas, E. (2011): «El compromiso de maestros y maestras en la constitución del sistema literario infantil y juvenil gallego», en Literatura Infantil y Juvenil y Diversidad Cultural/Literatura para a Infância e Juventude e Diversidade Cultural. Vigo/Braga, ANILIJ/ELOS/CIEC (Universidade do Minho), pp. 15-38.

- (2012): «Un berro silencioso contra a barbarie: Corredores de sombra, de Agustín Fernández Paz», en A narrativa xuvenil a debate (2000-2011). Vigo/Santiago de Compostela, Xerais/LIJMI, pp. 155-168.

Agrelo Costas, E. - Mociño GonZÁlez, I. (2008): «A silenciosa subversión do universo femenino como consecuencia da Guerra Civil: A sombra descalza, de An Alfaya», en A guerra civil española na narrativa infantil e xuvenil. Vigo, Xerais/LIJMI pp. 195-206

AlfayA, A. - VÁZQuez Freire, M. (2009): «Os Libros/As palabras da memoria», en A Memória nos Livros: História e histórias, Porto, Deriva, pp. 82-102.

ARÉN, R. - RodríGUEZ, P. (2006): Un río de sangue e tinta. Boiro, Concello de Boiro.

Beckett, S. (2008): Crossover Fiction. Global and Historical Perspectives. Hoboken, Taylor \& Francis.

Bertrand De Muñoz, M. (1982): La guerra civil española en la novela. Madrid, José Porrúa Turanzas.

BLANCO, C. (1991): Literatura galega da muller. Vigo, Xerais.

Even-Zohar, I. (1993): «A función da literatura na creación das nacións de Europa», Grial, XXXI/120, pp. 441-458.

(1994): «La función de la literatura en la creación de las naciones de Europa», en Avances en Teoría de la Literatura: Estética de la Recepción, Pragmática, Teoría Empírica y Teoría de los Polisistemas. Santiago de Compostela, Universidade de Santiago de Compostela, pp. 357-377.

- (1999): «Planificación de la cultura y mercado», en Teoría de los Polisistemas: estudio introductorio, compilación de textos y bibliografía. Madrid, Arco/Libros, pp. 71-96. Tb. en http://www.tau.ac.il/ itamarez/works/papers/trabajos/index.html [última consulta, 27-9-2013].

FERNÁNDEZ VÁZQUEZ, M. (2012). «María Xosé Queizán e a subversión do rol feminino na literatura xuvenil galega», Malasartes. Cadernos de Literatura para a Infância e a Juventude, (en prensa).

FERreIRA DA Silva, V. R. (2011). «Dragal. A herdanza do dragón, de Elena Gallego Abad», en Malasartes. Cadernos de Literatura para a Infância e a Juventude, 21-22, pp. 114-115.

FigueroA, A. (1988): Diglosia e texto. Vigo, Xerais. 
(2001): Nación, literatura, identidade. Comunicación literaria e campos sociais en Galicia. Vigo, Xerais.

GonZÁlEZ-MilláN, X. (1995): «O discurso literario galego e a configuración dun espacio público nacional no primeiro tercio do século XX: un marco de reflexión», en Tentativas sobre Dieste. Santiago de Compostela, Sotelo Blanco, pp. 14-29.

MociÑo GonZÁlez, I. (2013), «A materia artúrica ás voltas», El Correo Gallego, «Tendencias», «Literatura Infantil e Xuvenil», «Elos de lectura» (19 de marzo), p. 43

NeIRA Rodríguez, M. (2007): «Corredores de sombras», Malasartes. Cadernos de Literatura para a Infância e a Juventude, 15, pp. 80-81.

NeIRA VILAS, X. (2009): «Xograres dun tempo novo», El Correo Gallego, «Cancela aberta» (7 de junio), p. 4.

Roig ReCHOU, B. A. (2001): «Achega para unha periodización da Literatura Infantil e Xuvenil galega na actualidade», en Actas do Congreso literatura galega e do norte de Portugal. Santiago de Compostela, Xunta de Galicia, pp. 109-126.

(2002): «La literatura infantil y juvenil en Galicia» / «A Literatura Infantil e Xuvenil en Galicia», en La Literatura desde 1936 hasta principios del siglo XXI: Narrativa y traducción/A literatura dende 1936 ata principios do século XXI: Narrativa e traducción, A Coruña, Hércules, pp. 382-501.

- (2004): «O pracer de ler», Revista Galega do Ensino, 42, pp. 161-169.

(2005): «Literatura infantil e xuvenil en Galicia: dos inicios á consolidación», en Para entenderte mellor. As literaturas infantís e xuvenís do marco ibérico. Boletín Galego de Literatura, 32, pp. 141-167.

(2008a): La Literatura Infantil y Juvenil Gallega en el siglo XXI. Seis llaves para entenderla mejorl A Literatura Infantil e Xuvenil Galega no século XXI. Seis chaves para entendela mellor. Madrid/Santiago de Compostela, Asociación Española de Amigos del Libro Infantil y Juvenil/Xunta de Galicia.

(2008b): «A Guerra Civil na narrativa infantil e xuvenil galega: unha temática incompleta», en A guerra civil española na narrativa infantil e xuvenil. Vigo, Edicións Xerais de Galicia/LIJMI/ Fundación Caixa Galicia, pp. 69-102.

- (2009): «Antonio García Teijeiro. Un clásico contemporáneo da Literatura Infantil e Xuvenil galega», Malasartes. Cadernos de Literatura para a Infância e a Juventude, 17, pp. 13-17.

- (2010): «Da literatura para a infància à literatura de fronteira: Agustín Fernández Paz e Lygia Bojunga», Estudos de literatura brasileira contemporànea, 36, pp. 153-171

— , coord. (2011a): A Crítica e a Literatura Infantil e Xuvenil. Escrita Contemporánea. Q. A Coruña, Asociación de Escritores en Lingua Galega (AELG)/Comisión executiva da Sección de Crítica da AELG. 
(2011b): «A Representação do Sistema Educativo e dos Professores numa Selecção de Obras Narrativas que tratam a Guerra Civil Espanhola», en Globalização na Literatura Infantil. Vozes, Rostos e Imagens. Raleigh (N. C.), Lulu Entreprises, pp. 159-183.

(2012): «La guerra civil española aludida y recordada. Obras de fronteras, ambivalentes, crossover», en Literatura Infantil y Juvenil y Diversidad Cultural/Literatura para a Infância e Juventude e Diversidade Cultural. Vigo/Braga, ANILIJ/ELOS/Centro de Investigação em Estudos da Criança (Instituto de Educação - Universidade do Minho), pp. 529-548.

(2014): Historia da Literatura Infantil e Xuvenil galega. Vigo, Xerais (en prensa).

— coord. (1996-2013): Informe de Literatura. Santiago de Compostela: Xunta de Galicia/Centro Ramón Piñeiro para a Investigación en Humanidades, en http://www.cirp.es/rec2/informes/ [última consulta, 27-9-2013].

Roig Rechou, B. A. - Lucas Domínguez, P. - Soto LóPez, I., coords. (2008): A guerra civil española na narrativa infantil e xuvenil. Vigo, Xerais.

Roig Rechou, B. A. - Agrelo Costas, E. - Neira Rodríguez, M. - Mociño González, I. VÁZQUEZ GARCíA, C. (2009): «A memoria histórica a través da Literatura Infantil e Xuvenil en galego», en A Memória nos Livros: História e histórias. Porto, Deriva, pp. 55-72.

Roig Rechou, B. A. - NeIRA Rodríguez, M. (2010): «El papel de la mujer en la literatura infantil y juvenil gallega hasta el año 2006», en Diálogos intertextuales 3: en busca de la voz femenina. Temas de género en la literatura infantil y juvenil de la Península Ibérica y Latinoamérica. Frankfurt, Peter Lang GMBH, pp. 329-348.

Roig Rechou, B. A. - RuzickA Kenfel, V. - RAmos, A. M. (2012): La Guerra civil española en la narrativa infantil y juvenil (1936-2008). Porto/Santiago de Compostela, Tropelias \& Companhia/Servizo de Publicacións e Intercambio Científico da Universidade de Santiago de Compostela.

Roig Rechou, B. A. - Ruzicka Kenfel, V., coords. (2013): The Representations of the Spanish Civil War in European Children's Literature. Berna, Peter Lang (en prensa).

Soto LóPEZ, I. (2008): «Literatura contra a desmemoria: unha lectura de Noite de voraces sombras, de Agustín Fernández Paz», en A guerra civil española na narrativa infantil e xuvenil. Vigo, Xerais, pp. 251-269.

- (2009): «Agustín Fernández Paz: procesos de reescrita», Malasartes. Cadernos de literatura para a infância e a juventude, 18, pp. 26-28.

Sotomayor SÁEZ, M. V. (2001): «Literatura en serie», en La literatura infantil en el siglo XXI. Cuenca, Ediciones de la Universidad de Castilla-La Mancha, pp. 41-65.

TARrío VArela, A. (1994): Literatura galega: Aportacións a unha Historia crítica. Vigo, Xerais. THIESSE, A. M. (1999): La Création des identités nacionales. Europe XVIII-XX siècle. París, Seuil. 